\title{
Island biogeography on a micro-scale: Larger anammox granules not only harbor higher species diversity but also support more functional diversity
}

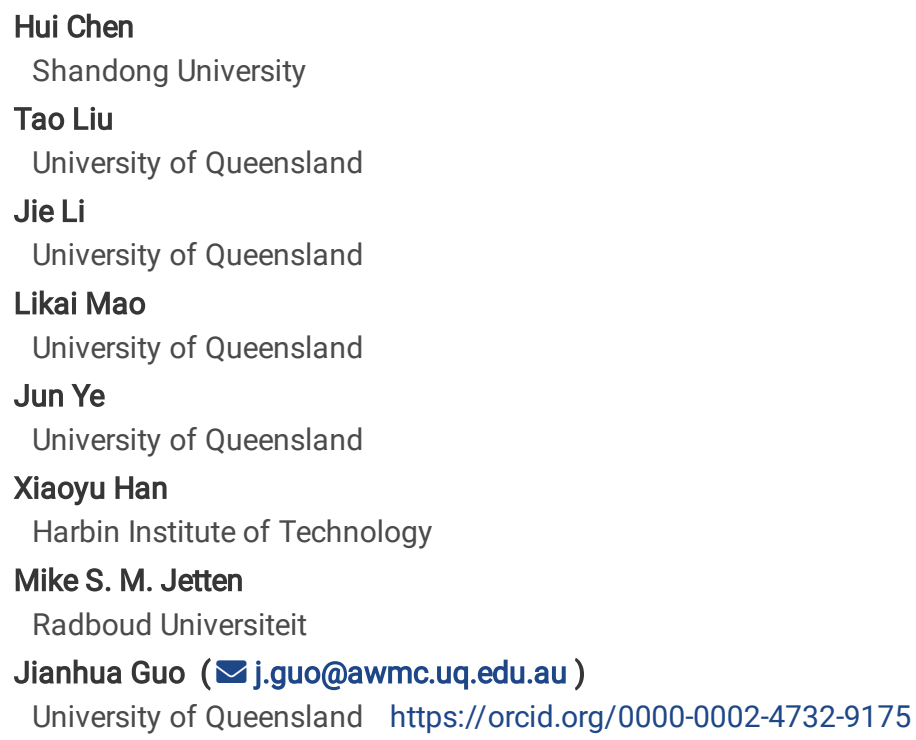

Research

Keywords: island biogeography, anammox bacteria, granule, microbial community structure, metagenomics, metatranscriptomics

Posted Date: March 25th, 2020

DOI: https://doi.org/10.21203/rs.3.rs-18517/v1

License: (c) (i) This work is licensed under a Creative Commons Attribution 4.0 International License. Read Full License 


\section{Abstract}

Background: According to the theory of island biogeography, there is a strong relationship between the species diversity and the isolated area. However, it is unclear whether the ecological distribution of microorganisms follows this island biogeography pattern at micro-scale. Here, we use microbial granules harvested from a partial nitritation and anammox (PN/A) system as a model to test if the microbial and functional diversity follow the island biogeography. We collected and divided these granules into five discrete size-fractions $(<0.2,0.2-0.5,0.5-0.8,0.8-1.0$ and $>1.0$ $\mathrm{mm})$.

Results: By comparing the composition and functional attribute of five pools of the size-fractionated granules by 16S rRNA gene amplicon, metagenomic and metatranscriptomic sequencing, larger granules were shown not only to harbor higher microbial diversity, but also to support more diverse functions than smaller granules. De novo co-assembly and binning of metagenomic reads yielded 22 near-complete genomes of dominant microorganisms, which allowed us to infer an ecological model of the microbial ecosystem in anammox-based granules. This genomebased ecological model indicates that nitrifying organisms in smaller granules feed nitrite to anammox bacteria in larger granules.

Conclusion: Our findings substantiate that microbial communities in PN/A granules follow a species-volume relationship, suggesting the generality of the theory of island biogeography on microscopic scale.

\section{Introduction}

For centuries, ecologists have studied how the diversity and functional traits of plant and animal communities vary across biomes, and have developed a number of ecological theories that interpret some of the observed general patterns. The theory of island biogeography is one of classic tenets and has been well tested at macro-level, where species richness (e.g., animals and plants) is a function of island characteristicsnotably the island size and remoteness (accessibility of islands to colonizing organisms) [1, 2]. Generally, larger island houses more species diversity and possesses larger absolute population size. However, despite important advances in evolutionary and conservation biology, the question regarding whether larger island harbors more microbial diversity and functional diversity is yet to be verified at a microscopic scale. Currently, there is much dispute regarding whether microorganisms have distinct biogeographies [3, 4], or whether all microorganisms have a cosmopolitan distribution, as presumed by the cosmopolitan theory of Baas-Becking that 'everything is everywhere' and the prevailing environmental conditions select [5]. According to the traditional cosmopolitan theory, the microorganisms are universally dispersed without impediment which would make biogeographic patterning unlikely due to fewer constraints of distribution and high population densities [4, 6]. In contrast, recent studies using molecular techniques suggested that microbial diversity in natural ecosystems follows biogeographical patterns that are similar to those observed for plants and animals [7-9], where an increase in the number of taxa is observed with increasing sample area. For example, Bell et al. [7] observed that the bacterial diversity (taxon richness) in water-filled treeholes, taken as islands, tended to increase with water volume (island size), which can be explained by the theory of island biogeography.

In contrast to the studies in natural ecosystems [7-9], we have just begun exploring similar questions for microbial communities in engineered ecosystems, where microbial communities are assembled by function, and render ecosystem service for the benefit of mankind. With increasing reliance on engineered ecosystems (e.g., wastewater treatment and bioremediation), the understanding of the microbial ecology has become essential for improving the efficiency and robustness of engineered systems [10,11]. For instance, the one-stage partial nitritation and anammox (PN/A), which combines aerobic ammonia oxidation with anaerobic ammonium oxidation (anammox), is a microbially mediated technology for treating ammonium-containing wastewater [12]. In the PN/A process, ammonia-oxidizing bacteria (AOB) oxidize about half of ammonium to nitrite while consuming the available but limiting oxygen, and anammox bacteria (AMX) convert the generated nitrite and the other half of ammonium into dinitrogen gas in the anoxic environment, with the production of some nitrate (Reaction: $\mathrm{NH}_{4}^{+}+1.32 \mathrm{NO}_{2}^{-} \rightarrow 1.02 \mathrm{~N}_{2}+2.03 \mathrm{H}_{2} \mathrm{O}+$ $0.26 \mathrm{NO}_{3}{ }^{-}$) [13] . Compared to the conventional two-stage nitrification/denitrification, the PN/A process exhibits several advantages, including no need for carbon source, less oxygen demand, less sludge production and less $\mathrm{N}_{2} \mathrm{O}$ emission (a potent greenhouse gas) [14]. Granulation is an important strategy to retain sufficient biomass in the reactor, especially when dealing with AMX which grow slowly (with a doubling time ranges from 3 to 20 days) $[15,16]$. Granule-associated bioreactors are intriguing systems for the consideration of biogeographic patterns, as granules provide well-replicated and clearly defined habitats for testing ecological theory. Granules in these bioreactors, like isolated oceanic land masses, are discrete and island-like habitats, which could be considered as "microscopic islands". Therefore, we hypothesized granules with different sizes represent microscopic islands with different island areas, thus affecting microbial diversity and functional diversity [17, 18].

Culture-independent molecular techniques have been used to characterize microbial communities in granule-based PN/A systems [19, 20]. These studies have provided insights of the taxonomic composition (in particular key nitrogen cycling microorganisms), but the interactions and differences of microbial and functional diversity among and within granules with different sizes remain not well explored.

Metagenomic/metatranscriptomic sequencing, the direct sequencing of the collective genomes in a given sample, enables to gain a more comprehensive understanding of microbial communities and a more detailed distribution of the networked metabolic interactions among anammox granules [21]. For example, previous studies combining metagenome and/or metatranscriptome have provided insights into the 
interactions of anammox and heterotrophic bacteria [22, 23], as well as suggested a clear variation in $\mathrm{N}$ cycling genes among different microbial aggregates (e.g., suspended biomass, biofilm, and granule) [24, 25]. However, all of these studies were conducted based on the premise that the granules present in a uniform size. In reality, the granules have a heterogenetic size distribution, and microbial diversity and functional diversity of PN/A granules might vary in complex patterns in response to granule size [26]. Thus, it is required to consider the granule size distribution in order to gain a more comprehensive view of changes of functional capabilities across size-fractions, and the extent to which microbial metabolisms are partitioned between size-fractionated granule communities. In this way, the microbial populations can be analysed at multiple scales within and among granules, which function as microbial "archipelagos".

The current study was designed to study the microbial biogeography by using a pilot-scale granule-based PN/A reactor as a model system. We hypothesized that the microbial communities found in the large size-fractions might be taxonomically and functionally distinct compared to those found in smaller fractions. This was predicted based on the fact that, from a macro-scale view, the biodiversity of island is affected by the island size, where larger island provides a wider variety of habitats, so species will diversify to fill up the available habitats [1]. Granules from a pilotscale PN/A reactor were collected and separated to five size-fractions $(<0.2,0.2-0.5,0.5-0.8,0.8-1.0$ and $>1.0 \mathrm{~mm})$. We combined $16 \mathrm{~S}$ rRNA gene amplicon, metagenomic and metatranscriptomic sequencing to investigate the differentiation of microbial diversity and functional diversity among the size-fractions. Moreover, based on the assembled draft genomes and mathematic modeling, we sought to delineate an ecological model of the microbial and metabolic interactions within and between size-fractions in the PN/A reactor by using multiple granule sizes instead of the use of a uniform size. We demonstrate that microbes inhabiting in the PN/A granules exhibit species-volume relationship. Our findings gave insight into the island biogeographical theory of microorganisms in water engineered ecosystems at a microscopic scale.

\section{Results And Discussion}

\section{Microbial community overview of size-fractionated PN/A granules}

The pilot-scale reactor had been in operation continuously for more than 500 days before the sampling. The influent was rich in ammonium (1724 $\pm 846 \mathrm{mg} \mathrm{N} \mathrm{L}^{-1}$ ) and contained residual organic carbon (336 $\pm 116 \mathrm{mg} \mathrm{COD} \mathrm{L}^{-1}$ ) (Table S1). The reactor was oxygen limited via continuous aeration resulting in dissolved oxygen DO values of $0.5-1.0 \mathrm{mg} \mathrm{L}^{-1}$. Stable PN/A performance was achieved in terms of an average total nitrogen removal rate of $0.82 \mathrm{~kg} \mathrm{~N} \mathrm{~m}^{-3} \mathrm{~d}^{-1}$ and efficiency of $87 \%$.

The microbial community structure of the PN/A granule samples was characterized using the combination of 16S rRNA gene sequencing and metagenomic sequencing based on Illumina technology. Taxonomic analyses based on 16S rRNA gene sequencing showed that, microbial communities in granules with different sizes were dominated by members of Proteobacteria (24 46\%), Chlorobi (14 34\%), Bacteroidetes (11 20\%), Chloroflexi (8 11\%) and Planctomycetes (0.5 10\%) (Fig. 1). These bacterial phyla are known to be relatively abundant and ubiquitous in PN/A granules $[20,22,23]$ and these five phyla accounted for at least $87 \%$ of all sequencing reads in granules of all size-fractions in this study. In addition, it was observed that the relative abundance of these members changed with increasing of granule size. Proteobacteria, accounted for $46 \%$ of all sequences in $<0.2 \mathrm{~mm}$ size fraction, while decreasing to $27 \%$ in $>1.0 \mathrm{~mm}$ size-fraction. Similarly, Bacteriodetes were consistently enriched in the smaller size-fractions, where they constituted of $20 \%$ all sequences in $0.2-0.5 \mathrm{~mm}$ size-fraction (versus $11 \%$ in $>1.0 \mathrm{~mm}$ sizefraction). In contrast, clades of Planctomycetes and Chloroflexi were consistently enriched in the larger size-fractions. Sequences matching WS6 and Acidobateria represented relatively minor components of the total amplicon sequences ( $1.6 \pm 1 \%$ and $1.3 \pm 1 \%$, respectively), but showed more abundances in large size-fractions. A previous study has predicted a fermentative and denitrifying role in the anaerobic granule core for WS6 and Acidobacteria, respectively [22]. It was surprising that each size-fraction also contained different bacterial communities, with a range of 2.3-7\% of unique OTUs in each size-fraction (Fig. S2), supporting the fact that they harbor distinct habitats. For example, Zoogloea was only present in the $<0.2 \mathrm{~mm}$ size-fraction, whereas Opitutus was only observed in the $>1.0 \mathrm{~mm}$ size-fraction.

Although similar taxonomic distributions were observed in metagenomic datasets, some differences were found in terms of species abundance, such as a slightly higher representation of Chloroflexi, Planctomycetes and Acidobacteria in metagenomic sequencing compared to 16S rRNA gene sequencing. Also, some phyla were less represented (e.g., Bacteriodetes and Chlorobi) in metagenome than in 16S rRNA gene sequencing datasets. Such differences could be partly explained by biases derived from the PCR process in amplicon sequencing [27]. Additionally, 16S rRNA gene recovered from the metagenomics data can span the entire length of the gene, whereas the PCR-based amplicon approach only targets specific region. The differences in accuracy of taxonomic assignments with various regions of the 16S rRNA gene may lead to the observed discrepancies with the two approaches [28].

Metagenome co-assembly and binning yielded 22 high-quality (> $80 \%$ completeness and $<4 \%$ contamination rates) MAGs (Table 2 ). The phylogenetic inference (Fig. 2) showed that these 22 MAGs spanned 8 phyla, including Proteobacteria, Planctomycetes, Bacteriodetes, Chloroflexi, Verrucomicrobia, Acidobacteria, Chlorobi, and Omnitrophica. The recovered genomes in the PN/A granules mostly resemble those of previously detected organisms in other PN/A system [22]. Among the recovered genomes were characterized taxa known to be involved in the canonical PN/A process: Nitrosomonas (AOB) encoded the key enzyme for ammonia oxidation (amo) (Fig. S3); and Candidatus Kuenenia (AMX) contained the core genes for hydrazine metabolism ( $h z s$ and $h d h$ ) and the gene cluster for nitrite reduction (nir), all essential for the anammox process. In 
addition, a few of organisms (e.g., PTB1-4, and CFX1-3) were capable of nitrate/nitrite respiration, which was evident from the genes encoding nitrate/nitrite reductase (e.g., nar and nir). Among them, only PTB3 and PTB4 encoded a complete denitrification pathway from nitrate to dinitrogen gas (Fig. S3), suggesting their potential roles in removing organic carbon and nitrate.

\section{Larger size fractions harbor more diverse communities and sustain more redundant functions}

In order to investigate the difference of the species diversity among size-fractions, we calculated alpha-diversity indices (including ACE and Chao1 for richness, and Shannon $\mathrm{H}$ and Simpson D for diversity) based on the 16S rRNA gene sequencing results (Table 1). Granule size explained the increasing number of OTUs (species) in larger size-fraction, ranging from $356(<0.2 \mathrm{~mm})$ to $434(>1.0 \mathrm{~mm})$. Similarly, the microbial richness, as indicated by the estimators ACE and Chao1, generally showing an increasing trend along with the granule size (except for 0.2-0.5mm size-fraction being the lowest). In addition to granule size, microbial richness could also be affected by biotic factors such as competition and facilitation, and abiotic factors such as nutrient availability and disturbance frequency [29]. In terms of microbial diversity, Shannon $\mathrm{H}$ rose from 3.19 in $<0.2 \mathrm{~mm}$ size-fraction to 3.83 in $>1.0 \mathrm{~mm}$ size-fraction; whereas Simpson D showed the lowest value of 0.0735 for $0.8-1.0 \mathrm{~mm}$ size-fraction and the highest of 0.1347 for $<0.2 \mathrm{~mm}$ size-fraction (overall showing a downward trend). Both the increasing Shannon $\mathrm{H}$ and decreasing Simpson $\mathrm{D}$ in larger granules indicate that larger size-fraction contain higher microbial diversity in this PN/A system.

According to the theory of island biogeography, there is a strong species-area relationship at macro-scale. As shown in Fig. 3A, taxonomic diversity contained within each size-fractions increased with increasing granule size, showing an approximately linear growth. The granules with $>1.0 \mathrm{~mm}$ size-fraction present the most diverse community, whereas the $<0.2 \mathrm{~mm}$ size-fraction had the lowest diversity. Considering the granule have a three-dimensional habitat distribution, which means microorganisms can grow on the inner layer of granules, rather than only growing on the surface of an island. Thus, we test whether the ecological distribution of microorganisms in granules follows a species-volume relationship (Fig. 3B). A sharp increase of the taxonomic diversity was observed in granules with volume smaller than $0.38 \mathrm{~mm}^{3}$ ( $<1.0 \mathrm{~mm}$ size-fractions), while there was a slow increase in taxonomic diversity in granules larger than $0.38 \mathrm{~mm}^{3}(>1.0 \mathrm{~mm}$ size-fraction). The elevated diversity in larger granule has been shown to coincide with previous studies of PN/A granules in lab-scale reactors [19, 20]. Taxa are usually adapted to a particular habitat, and large granules contain more distinct layered habitats due to the mass transport limitation of nutrient [30-33]. Therefore, large granules could support the survival of more species.

Functional diversity has been used to reveal the diversity and distribution of functional traits (or functional genes) across communities [34, 35]. Here we used Shannon's diversity index to indicate functional diversity [35], estimated from the diversity of the protein-coding genes categories identified from annotated metagenomic reads. Similar to the distribution of taxonomic diversity among size-fractions, the communities found in small size-fractions typically had lower level of functional diversity (Fig. $3 \mathrm{C}$ and D). This is likely a result of that large granule having more anaerobic habitats suitable for the growth of anaerobes, therefore expressing a broader array of genes associated with anaerobic pathways (e.g., methanophenazine hydrogenation and dipicolinate synthesis). With granule size larger than $1.0 \mathrm{~mm}$, interestingly, no increase in the functional diversity was observed despite increasing species richness along with the increasing granule size. It is widely assumed that community diversity could be decoupled with functioning [36, 37]. With a certain microbial diversity, additional species would not bring significant additional functional benefits [38]. Multiple microbial taxon can carry out the same process within an ecosystem, thus resulting in the functional redundancy, where the system can perform just as well with fewer species. Considering both functional diversity and the taxonomic diversity, we found that the overall diversity of functional gene categories found in a given sample was, to some degree, predictable from taxonomic diversity of the microbial communities. It should be noted that the samples collected in this study were from one steady-state PN/A system. Future investigations on more granule-based systems might be required to confirm our observations of this work and would be better for a more comprehensive comparison.

\section{Nitrogen conversion microorganisms and metabolic pathways in different size-fractionated granules}

A PN/A bioreactor is a nitrogen-driven ecosystem, and its stable performance relies on achieving an appropriate balance between the activities of the principal microbial protagonists therein, including $A M X$ and $A O B$, while suppressing or washing out nitrite-oxidizing bacteria (NOB). Here, we specifically analyzed the populations involved in nitrogen cycle of the five size fractions based on both 16S rRNA gene and metagenomic sequences. Anammox bacteria were proportionally enriched in larger size-fractions (Table S2). Sequencing matching anammox Candidatus Kuenenia with a similarity of $99.6 \%$ (classified as Planctomycetes in Fig. 1) peaked in relative abundance (9.4\% of total) in $>1.0 \mathrm{~mm}$ size-fraction, while decreased to $5.3 \%$ in $0.5-0.8 \mathrm{~mm}$ size-fraction and were nearly negligible in $<0.2 \mathrm{~mm}$ size fraction (0.3\%). Their elevated abundances in the larger size fractions are understandable since Candidatus Kuenenia is inhibited by oxygen [39], which favors more anaerobic space in larger granules due to a longer oxygen permeation depth [32, 33]. Conversely, the relative abundance of the sequences matching a typical AOB, i.e. Nitrosomonas (classified as Proteobacteria in Fig. 1) showed an opposite trend, peaking at $33.8 \%$ of the total $<0.2 \mathrm{~mm}$ size-fraction amplicons, compared with $5.7-6.4 \%$ in $>0.8 \mathrm{~mm}$ fractions. Since smaller granules have higher surface/volume ratio, which provide larger aerobic volume fraction [40], the enrichment of Nitrosomonas in small granules is consistent with these bacteria being aerobes adapted for the efficient use of oxygen. The presence of Nitrospira (one of the typical NOB), which could negatively affect nitrogen removal efficiency by competing nitrite with anammox bacteria, was negligible with an abundance of $0.01-0.3 \%$ across all size-fractions. Additionally, a typical heterotrophic denitrifier, Denitratisoma (classified as Proteobacteria in Fig. 1), was also observed in all the granules, which can utilize the organic carbon for nitrate/nitrite 
removal. The relative abundance of this organic carbon-scavenger increased from $3.8 \%$ (<0.2 mm-granules) to $8.6 \%$ (0.8-1.0 mm-granules), because larger granules harbour more anaerobic zones supporting their growth by taking up nitrite/nitrate as the electron acceptors.

Functional screening of the metagenomic and metatranscriptomic datasets revealed genes and transcripts involved in nitrogen metabolisms across size-fractions, which were correlated with the presence of the functional microorganisms (Fig. 4 and Table S2). In both the geneabundance and gene-expression levels, the key nitrogen-related genes, were detected in all granules with different sizes. Specifically, the core genes and transcripts involved in hydrazine metabolism ( $h z s$ and $h d h$ ), which are all essential for anammox process, were expressed in larger granules, suggesting that larger size fractions predominantly performed the anammox process. In contrast, nitrification is the predominant nitrogen metabolism in the smaller granules, where the key genes and transcripts encoded for ammonia oxidation enzymes (amo and hao) were more abundant. Additionally, genes that encode catabolic enzyme specific for denitrification, including napA, nar, nirK, nor and nosZ, were low in abundance and expression compared with those involved in anammox and nitrification process. The counts of genes and transcripts generally show an increasing trend along with granule size, whereas $0.8-1.0 \mathrm{~mm}$ granules have the highest transcript hits.

Based on the established mathematical model, the microbial stratification inside the granules was also investigated (Fig. S4). Overall, anammox bacteria were shown to dominate the larger granules (0.6-1.2 $\mathrm{mm}$ ) while AOB were predicted to be present in the smaller granules (0.1-0.3 mm. The model showed that the NOB were out selected in all granule sizes in the competition with anammox and heterotrophic denitrifiers. These model predictions are in accordance with metagenomic and metatranscriptomic results. The good match between the experimental and simulation results supported the relationship between microbial stratification and granule size. Specifically, in 0.1-0.3 mm granules, AOB occupy the granule surface where oxygen and ammonium are sufficiently present, while heterotrophs dominate the inner layer. In the granules with radius of 0.6-1.2 mm, anammox bacteria gradually develop at the inner side of the granule, with the relative distribution of AOB and heterotrophic bacteria unchanged at outer layer. Anammox bacteria are outcompeted by heterotrophs at outer shell of the granule mainly due to the inhibition of oxygen at the granule surface. The predicted microbial stratification inside biofilm (Fig. S4) remains to be experimentally verified by using advanced methods (e.g., 3D-FISH and microsensor).

Overall, the fraction-specific distribution was evident for key nitrogen-involving taxa, genes and transcripts, as well as the microbial stratification inside biofilm matrix. These patterns suggest that the small granule plays a dominant role in ammonium oxidation that is critically dependent on access to sufficient oxygen, and the removal of the produced nitrite will mostly rely on the anammox and heterotrophic denitrification in large granule. However, as large granules provide habitats for both aerobes and anaerobes, it is capable of complete nitrogen removal, but the availability of nitrite will restrict the overall nitrogen removal rate. Additionally, the stratified biofilm was determined by the availability and inhibition effect of specific substrates (e.g., nitrite and oxygen). Variable granule size distribution may drive heterogeneity in nitrogen removal performance in PN/A process.

\section{Granular aggregate as a microscopic model system for island biogeography}

Island biogeography theory is one of the most influential paradigms in ecology, which is central to several disciplines (e.g., conservation ecology and metapopulation theory) and continues to provide insights into research of island-like systems [41-44]. For example, Ali, Wang, Salam, Hari, Pronk, Van Loosdrecht, Saikaly [44] observed that the species sorting was significantly higher in flocs and small granules than large granules in aerobic granular sludge system, while putative functional populations were enriched with an increase in microbial aggregates size. Here, we adopted the theory of island biogeography as a conceptual framework for understanding the microbial ecology of microbes within a granulebased PN/A bioreactor. Granules, as insular habitats, provide favorable microscopic habitats for microorganisms. Viewing granules as islands in a bioreactor of potential colonists, increasing taxonomic diversity in larger size-fractions was shown to be congruent with the theory of island biogeography as the microbial richness was largely dependent on the size of the island [1] and larger islands house more taxa [7] (Fig. 3).

The observed increase in microbial diversity can be partially explained by the increased micro-habitats diversity and substrate-transmission complexity that associated with a larger granule. Firstly, larger granule provides better habitat differentiation and the enhanced heterogeneity, which foster more functional populations. Specifically, the large granules do have an anaerobic layer at the inner core that accommodates populations of other physiological types of bacteria. Secondly, each of the granule houses a micro-ecosystem that derives its nutrients and energy from wastewater. The availability of nutrients/substrate that may favor different bacterial species to colonize and perform differently. In PN/A reactor, the availability of oxygen, to a large extent, differentiates the microbial communities of small granules from large granules. The substrate (e.g., oxygen) drawdown from the outer layer to the inner core of granules significantly restructures the microbial ecosystem in granules, resulting in the differences in the abundances and the activities of aerophilic or anaerobic microbes. Large granules offer more favourable habitat for anaerobic bacteria (e.g., heterotrophic bacteria) that are capable of anaerobically decomposing organic matter within the anoxic core of the granules. Aerobic COD degradation in small granules and on the surface of large granules, together with anaerobic COD degradation in the core of large granules contributed to the COD removal in this PN/A system (as indicated by the COD removal efficiency in Table S1).

It is worth to note that PN/A granules are recirculated in the bioreactor, which make the scenario of the interaction and overview of microbial ecology in granules more complicated. Taking the bioreactors as a whole, where a group of granules closely scattered in the bioreactor, numerous 
of granules form an archipelago and there were reciprocal interactions between these islands. Under such circumstance, a higher immigration rate of species is expected, which might reduce the species differences between size-fractions.

Overall, granules function as islands for housing microorganisms, in which larger granules not only harbor higher microbial diversity, but also support more functional diversity. The theory of island biogeography is instructive to understand the microbial ecology associated with granule. A better understanding of the microbial ecology in PN/A reactor could guide us to better design and operate bioreactors to foster the development of specific microbial communities that can support the desired functional processes [11].

\section{Integrating nitrogen cycling microorganism and activities in granules}

As indicated by the different expression of aerobic and anaerobic ammonium oxidation genes in size-fractionated anammox granules (Fig. 4), an ecological model based on the granule PN/A system with size distribution was delineated in Fig. 5. The small-size granules are dominated by AOB and heterotrophs, which catalyze aerobic oxidation of ammonium to nitrite and aerobic oxidation of organic carbon to $\mathrm{CO}_{2}$. On the other hand, both aerobic and anaerobic microorganisms ( $A O B$, anammox and heterotrophs) are observed in large-size granules, in which ammonium, produced nitrite and nitrate are removed to dinitrogen gas. It is also worth to note that NOB are rarely detected in all granules, thus the nitrate involved is mainly produced from anammox reaction and partially consumed by heterotrophic denitrification [15].

In small granules, AOB contribute to ammonium oxidation while heterotrophs contribute to COD oxidation. As the oxygen permeates along the entire small granules (0.1-0.3 mm) (Fig. S4), the anaerobic processes (anammox and heterotrophic denitrification) are both inhibited in small granules. Thus, the produced nitrite will escape from small granules and transfer to the larger granules. In large granules (0.6-1.2 mm), the oxygen permeation from surface ceases after 300-400 $\mu \mathrm{m}$, and the anaerobic layer can expand. In the anaerobic layer, both anammox and heterotrophic denitrification work together to remove nitrite either transferred from small granules or from the AOB growing at outer layer of the large granule itself. It is worth to note that the kinetics of anammox and heterotrophic denitrifiers selected were slightly higher than the average values [45]. Therefore, NOB are out-selected during the competition for nitrite with AMX and heterotrophic denitrifiers in the present model. In the real reactor, the out-selection of NOB could be due to the high free nitrous acids (FNA) and free ammonia (FA) concentrations under sidestream condition [46].

To quantify the nitrogen flows among granules, mass balance was analyzed based on the simulation results and the calculated biomass volume of each granule size. The granules with radius of $0.1 \mathrm{~mm}$, only contributed $4.2 \%$ to nitrite production which can be removed inside the same granules while the majority (95.8\%) will be transferred to the larger granules with radius of $0.6 \mathrm{~mm}(14.8 \%), 0.9 \mathrm{~mm}(46.5 \%)$ and $1.2 \mathrm{~mm}(34.5 \%)$. Similarly, about $14.4 \%, 45.3 \%$ and $33.7 \%$ of the produced nitrite in granules with radius of $0.3 \mathrm{~mm}$ will be transferred to $0.6 \mathrm{~mm}, 0.9 \mathrm{~mm}$ and 1.2 $\mathrm{mm}$ granules, respectively (Fig. 5). This cross-feeding of nitrite from small to large granules indicates the mutualism and competition in PN/A system occur not only inside granules, but also among granules with different sizes [47]. However, this cross-feeding of substrate is unidirectional (Fig. 5). The granules with radius of 0.6-1.2 mm could offer both aerobic and anaerobic conditions, which can foster AOB, anammox bacteria and heterotrophic bacteria at different micro-habitats (Fig. S4). By utilizing the ammonium, oxygen and organic carbon from the feeding, and the nitrite transferred from the smaller granules, these large granules can develop a stratified microbial community to utilize all these inputs by themselves with a balance. Thus, there is no substrate transferred from the large granules to the small granules. However, these results do not suggest that larger granules are better than smaller granules. Indeed, it was observed that the $\mathrm{N}_{2} \mathrm{O}$ production increased significantly in larger granules due to incomplete denitrification [48]. The optimal granule size in practice is determined based on the balance between nitrogen removal performance, greenhouse gas emission $\left(\mathrm{N}_{2} \mathrm{O}\right)$ and also the operational cost (maintaining large granules requires more energy consumption), which warrants further studies.

Although the microbial ecology of anammox granules was studied in previous studies $[22,23,25,49,50]$, the size-fractioned anammox granule system proposed here delineates the interactions among granules with different sizes from micro-scale view for the first time. In a recent study, the cross-feeding among microorganisms was investigated based on metagenomics analysis [50]. However, the present study touched another dimension to demonstrate the interactions between granules based on more comprehensive data (metagenomics and metatranscriptomics). The cross-feeding model proposed here offers an explanation for the granule size distribution impacts on PN/A performance.

\section{Conclusions}

Granules in a pilot-scale PN/A reactor were collected and divided into five discrete size-fractions $(<0.2,0.2-0.5,0.5-0.8,0.8-1.0$ and $>1.0 \mathrm{~mm})$. By comparing the composition and functional attributes of five size-fractionated granules by 16S rRNA gene amplicon, metagenomic and metatranscriptomic sequencing, larger granules were shown not only to harbor higher microbial diversity, but also to support more diverse functions than smaller granules. 22 near-complete genomes of dominant microorganisms were obtained using de novo co-assembly and binning of metagenomic reads. In addition, an ecological model was developed based on microbial characteristics and mathematical model, which indicated that nitrifying organisms in smaller granules feed nitrite to anammox bacteria in larger granules. Our findings substantiate that microbial communities in PN/A granules follow a species-volume relationship, suggesting the generality of the theory of island biogeography on microscopic scale. 


\section{Methods}

\section{Sample collection}

Granular samples were collected from a pilot-scale sequencing batch reactor (SBR) performing one-stage PN/A process, with a working volume of $60 \mathrm{~m}^{3}$. The reactor was completely mixed with sludge (granules) homogeneously distributed. The reactor was fed with the effluent from a primary clarifier of a full-scale WWTP (Beijing, China). Ammonium carbonate was added to the real wastewater to obtain an average ammonium concentration of $1700 \mathrm{mg} \mathrm{N} / \mathrm{L}$. The mean concentrations of chemical oxygen demand (COD) and phosphorus were $340 \mathrm{mg} / \mathrm{L}$ and $6 \mathrm{mg} P / \mathrm{L}$, respectively. Dissolved oxygen (DO) was maintained at $0.5-1.0 \mathrm{mg} / \mathrm{L}$ via an aeration control system. After long-term operation, this reactor achieved stable autotrophic nitrogen removal mediated by AOB and anammox bacteria (operational performance as shown in Table S1).

This pilot-scale reactor had been operated continuously for more than 500 days before the sampling. Since the granules were homogeneously distributed in the complete-mixing reactor, to collect representative samples, granular sludge (150 mL) was harvested from the middle of reactor. While single-granule based investigation is beneficial for the study [51], it is time- and cost-consuming. Therefore, based on the granular size, the sampled sludge was further fractionated into five groups by sequential sieving through a series of sieves $(0.2,0.5,0.8$ and $1.0 \mathrm{~mm}$ mesh) in a short time (<1 min). Five subsamples with different granular size P1 (<0.2mm), P2 (0.2-0.5mm), P3 (0.5-0.8mm), P4 (0.8-1.0mm) and P5 $(>1.0 \mathrm{~mm})$ were obtained (Fig. S1) and were instantly flash frozen in liquid nitrogen before storing at $-80^{\circ} \mathrm{C}$ for later DNA and RNA extraction. The relative abundances of each size-fraction were described in Table S3.

\section{Nucleic-acid extraction and sequencing}

Total genomic DNA and RNA were extracted from each of the five subsamples using the FastDNA SPIN Kit for Soil (MP Biomedicals, Santa Ana, CA, USA) and the Trizol kit (Invitrogen, Carlsbad, CA, USA), respectively, according to the manufacturer's protocols. The purity and concentration of the extracted DNA and RNA was detected using agarose gel electrophoresis an Ultra-micro spectrophotometer NanoDrop 2000 (Thermo Fisher Scientific, Waltham, MA, USA). For DNA library construction, DNA was fragmented to an average size of approximately 300 bp by ultrasonication (Covaris M220 series, Woburn, MA, USA) and the fragmented DNA were end-repaired, A-tailed and ligated to TruSeq adapters using a TruSeq ${ }^{\mathrm{TM}}$ DNA sample prep kit (Illumina, SanDiego, CA, USA). Following RNA extraction, total RNA samples are DNase-treated to remove contaminant genomic DNA. Depletion of ribosomal RNA (rRNA) was performed using a Ribo-Zero rRNA Removal Kits (Epicentre, Wisconsin, USA) following the manufacturer's instructions. The rRNA-depleted samples were then input into the TruSeq ${ }^{\text {TM }}$ RNA sample prep kit (IIlumina, SanDiego, CA, USA) for RNA-seq library preparation. Briefly, the purified RNA was fragmented and then reverse transcribed to cDNA with adaptors attached to the ends. Both DNA and RNA sequencing were performed on an Illumina Hiseq 2000 platform (Illumina, San Diego, CA) at Majorbio Bio-Pharm Technology Co., Ltd. (Shanghai, China).

An amplicon survey of a portion of 16S rRNA gene was carried out to provide a higher resolution and more in-depth analysis of the composition and diversity of various granule size fractions. Amplification of 16S rRNA genes from genomic DNA were conducted using the barcoded primer pair 338F/806R[52] that targets the V3-V4 regions of the 16S rRNA gene. DNA was amplified in triplicate following the protocol described previously [20], and the triplicate reactions of each sample were composited. Amplicon sequencing was conducted on an Illumina MiSeq platform (Illumina, USA) at Majorbio Bio-Pharm Technology Co., Ltd. (Shanghai, China), creating $2 \times 250$ bp paired-end reads. The resulted sequencing reads were de-multiplexed and quality filtered to remove low quality sequences using QIIME [53] with default parameters. And chimeric sequences were removed with UCHIME [54] with default parameters. Sequence reads were assigned into operational taxonomic units (OTUs) with 97\% similarity, taxonomy was assigned by aligning the representative sequences from each OTU against the Silva database [55].

\section{Metagenomic assembly, binning and phylogenetic analysis of recovered draft genomes}

Raw paired-end reads from the HiSeq platforms were initially filtered using Trimmomatic v0.36 [56] based on a minimum average quality score of 30 , a minimum sequence length of $50 \mathrm{bp}$. Paired-end reads were then merged using fq2fa program in IDBA-UD v 1.1.3 [57]. All read data were coassembled, that is, the data sets from five samples were combined and the 169 million reads were assembled de novo together, to obtain the maximum amount of biologically relevant information on contigs with an average coverage about 10 . Assembly was performed using the de novo assembler in IDBA-UD v 1.1.3 [57] with pre-correction and otherwise default settings. 135 million reads (79.7\% of the data, 18.6 Gbp) were incorporated in the assembled contigs. This assembly resulted in 144,876 contigs larger than 1,000 bp, and a total of 18,312 of these contigs were longer than $5,000 \mathrm{bp}$.

Assembled contigs greater than 2,500 bp were binned as metagenome-assembled genomes (MAGs) on the basis of abundance and tetranucleotide frequency using MetaBAT [58]. The completeness and contamination of the recovered genomes was assessed using CheckM [59], evaluated from number of marker genes present in genome and from the number of multi-copy marker genes respectively. Further analysis used only high-quality draft genomes, defined as bins that are near complete $(>80 \%)$ with low contamination $(<5 \%)$. 
For taxonomic analyses based on the metagenomic data sets, we identified and classified the 16S rRNA gene sequences from the metagenome contig files using the communityM tool (https://github.com/dparks1134/CommunityM) with Hidden Markov Models (HMM). The selected contigs were then mapped to the Greengenes database at $97 \%$ similarity with the Burrows-Wheeler Aligner (BWA) software, and operational taxonomic unit (OTU) table, showing the relative abundances of the microbial community population [60, 61], was generated.

Phylogenetic inference was conducted to classify the MAGs using genome taxonomy database (GTDB v2.1.15) [62]. Briefly, the MAGs were inferred based on a multiple sequence alignment of 120 single-copy marker proteins identified as being present in $\geq 90 \%$ of bacterial genomes and, when present, single-copy in $\geq 95 \%$ of genomes. The concatenated protein sequences were aligned to Pfam and TIGRfam hidden Markov models(HMMs) using HMMER61 v3.1b2 (http://hmmer.org/) with default parameters and tree was constructed using FastTree 2 v2.1.9 [63] under the WAG+GAMMA model using the approximately maximum likelihood method. This tree was then bootstrapped using genometreetk v0.0.35 (D. H. Parks, unpublished materials, https://github.com/dparks1134 /GenomeTreeTk), calculating bootstrap support from 100 FastTree iterations. The associated taxonomy was derived using NCBI annotations, and was used to decorate the tree using tax2tree [64] and adjusted manually. This tree was visualized in ARB v6.0.6 [65] and exported for further refinements in Adobe Illustrator.

\section{Metatranscriptomic analysis}

Quality filtering and merging of metatranscriptome sequences were carried out in the same manner as for metagenome sequences. Metatranscriptomic reads were mapped back to all assembled metagenomic contigs using STAR v020201 [66] following settings of ENCODE Long RNA-Seq processing pipeline (https://github.com/ENCODE-DCC/long-rna-seq-pipeline).

\section{Phylogenetic and functional diversity analysis}

To determine the diversity of the microbiome, we calculated the alpha diversity based on the 16S rRNA gene sequencing data sets and plotted it vs. granule volume and granule diameter. The microbial diversity was described by the OTU number, richness and diversity indices (Table 1 ), which was calculated in QIIME using a rarified data (22834 sequences per sample) that corrects for differences in sequencing depth.

Metagenomic and metatranscriptomic sequences were uploaded to MG-RAST (Rapid Annotation using Subsystems Technology for Metagenomes) for general functional annotation. Sequences were annotated against SEED subsystems databases with an e value of $10^{-5}$. Functional diversity were determined by calculating Shannon's diversity index from the level 3 gene categories (of which there were a total of 1107 across the 5 datasets) based on metagenomic annotation.

\section{Analysis of key nitrogen cycle inventory}

Analysis of protein-coding genes and transcripts for nitrogen metabolic pathways was performed using Prokka [67]. The targeted key enzymes includes: ammonia monooxygenase (amo), hydroxylamine oxidoreductase (hao), hydrazine synthase (hzs), hydrazine dehydrogenase ( $h d h$ ), periplasmic nitrate reductase (nap), membrane-bound nitrate reductase (nar), nitrite reductase (nir), cytc dependent nitric oxide reductase (nor), nitrous oxide reductase (nos), pentaheme nitrite reductase ( $n r f)$, nitrite oxidoreductase ( $n x r)$ and nitrogenase ( $n$ if). Read counts were calculated for each predicted open reading frame (ORF) using RSEM v1.2.31 [34] and normalized by sequencing depth and ORF length and expressed as Transcripts per million (TPM) values.

\section{Mathematical modeling}

A one-dimensional biofilm model was developed to simulate the bioconversion and microbial structure in the granule-based anammox process in the software AQUASIM 2.1d [68]. The model development was based on our previous study, which investigated the impacts of granule size distribution on one-stage anammox performance [45]. The biological model describes the relationships among six soluble species, i.e., degradable $\operatorname{COD}\left(S_{S}\right)$, ammonium $\left(S_{N_{H} 4}\right)$, nitrite $\left(S_{N 02}\right)$, nitrate $\left(S_{N 03}\right)$, nitrogen $\left(S_{N 2}\right)$, dissolved oxygen $\left(S_{O 2}\right)$, and six particulate species, including $A O B\left(X_{A O B}\right)$, $\operatorname{NOB}\left(X_{N O B}\right)$, anammox bacteria $\left(X_{A n}\right)$, heterotrophic denitrifiers $\left(X_{H B}\right)$, slowly degradable organic substrate $\left(X_{S}\right)$, as well as inert biomass $\left(X_{I}\right)$. For all the microorganisms, both growth and decay were included in the model (Table S4). Kinetic control of all the enzymatic reaction rates was described through the Michaelis-Menten equation. More details about the parameter definitions and kinetics values can be found in previous study [45]. The implementation of the granular sludge reactor model with five granule size classes in AQUASIM 2.1d was based on the method proposed by previous studies $[45,69]$. The essence of the model considering size distribution is dividing one single reactor into five subcompartments. Each of them is dominated by the granules with one size. According to the measured granule size distribution (Table S3), five granule sizes $(0.1 \mu \mathrm{m}, 0.3 \mu \mathrm{m}, 0.6 \mu \mathrm{m}, 0.9 \mu \mathrm{m}$ and $1.2 \mu \mathrm{m})$ were selected as the representative for each group. These five sub-compartments are connected with each other in order to simulate the conditions in one single reactor (the schematic modelling structure as shown in Fig. S5). Based on the simulated results, the mass balance was conducted to calculate the nitrogen flows among each sub-compartment. The effluent from each sub-compartment was used to compare with the final effluent from the reactor. Based on the established model, the spatial microbial stratification was studied. 


\section{Declarations}

\section{Ethics approval and consent to participate}

Not applicable.

\section{Consent for publication}

Not applicable.

\section{Availability of data and material}

Genomic DNA and RNA sequencing data can be found on the MG-RAST (Rapid Annotation using Subsystems Technology for Metagenomes) under Project ID mgp83671. Raw 16S rRNA gene sequencing data can be accessed from NCBI Sequence Read Archive (SRA) database (Accession Number: SRP080297).

\section{Competing interests}

The authors declare that they have no competing interests.

\section{Funding}

This work was financially supported by the Australian Research Council Discovery Early Career Researcher Award (DE 130101401).

\section{Authors' contributions}

JG designed the study. HC, XH and JL prepared samples for 16S rRNA gene, metagenomic and metatranscriptomic sequencing. TL developed the mathematical model. XH performed the sampling, preservation and nucleic acid extractions. HC, JL, LM and JY performed the microbial community analysis and the bioinformatics analysis. $\mathrm{HC}, \mathrm{TL}, \mathrm{MJ}, \mathrm{JY}$ and JG wrote the manuscript in consultation with all other authors.

\section{Acknowledgements}

Jianhua Guo would like to thank the support by the Australian Research Council through the Future Fellowship (FT170100196). Hui Chen would like to acknowledge the support of the International Postgraduate Research Scholarship (IPRS) and The University of Queensland Centennial Scholarship (UQCent). MSM Jetten is supported by ERC AG 339880 and OCW/SIAM 024002002.

\section{References}

1. MacArthur R, Wilson EO. The Theory of Island Biogeography. Princeton, New Jersey, USA: Princeton University Press; 1967.

2. Wardle DA, Yeates GW, Barker GM, Bellingham PJ, Bonner KI, Williamson WM. Island Biology and Ecosystem Functioning in Epiphytic Soil Communities. Science 2003;301:1717-20.

3. Fenchel T, Finlay BJ. Bacteria and Island Biogeography. Science 2005;309:1997.

4. Finlay BJ. Global Dispersal of Free-Living Microbial Eukaryote Species. Science 2002;296(5570):1061-3.

5. Baas-Becking LGM. Geobiologie of inleiding tot de milieukunde. The Hague, Netherlands: W.P. Van Stockum \& Zoon; 1934.

6. Fenchel T, Finlay BJ. The Ubiquity of Small Species: Patterns of Local and Global Diversity. Bioscience 2004;54(8):777-84.

7. Bell T, Ager D, Song JI, Newman JA, Thompson IP, Lilley AK, et al. Larger islands house more bacterial taxa. Science 2005;308(5730):1884.

8. Horner-Devine MC, Lage M, Hughes JB, Bohannan BJM. A taxa-area relationship for bacteria. Nature 2004;432:750-3.

9. Green JL, Holmes AJ, Westoby M, Oliver I, Briscoe D, Dangerfield M, et al. Spatial scaling of microbial eukaryote diversity. Nature 2004;432:747-50.

10. Vanwonterghem I, Jensen PD, Dennis PG, Hugenholtz P, Rabaey K, Tyson GW. Deterministic processes guide long-term synchronised population dynamics in replicate anaerobic digesters. ISME J 2014;8(10):2015-28.

11. Briones A, Raskin L. Diversity and dynamics of microbial communities in engineered environments and their implications for process stability. Current Opinion in Biotechnology 2003;14:270-6.

12. Lackner S, Gilbert EM, Vlaeminck SE, Joss A, Horn H, van Loosdrecht MC. Full-scale partial nitritation/anammox experiences-an application survey. Water Res 2014;55:292-303.

13. Jetten MSM, Strous M, Pas-Schoonen KTvd, Schalk J, Dongen UGJMv, Graaf AAvd, et al. The anaerobic oxidation of ammonium. FEMS Microbiology Reviews 1998;22:421-37. 
14. Liu T, Hu S, Guo J. Enhancing mainstream nitrogen removal by employing nitrate/nitrite-dependent anaerobic methane oxidation processes. Crit Rev Biotechnol 2019;39(5):732-45.

15. Strous M, Fuerst JA, Kramer EHM, Logemann S, Muyzer G, Pas-Schoonen KTvd, et al. Missing lithotroph identified as new planctomycete. Nature 1999;400:446-9.

16. Kartal B, van Niftrik L, Keltjens JT, Op den Camp HJ, Jetten MS. Anammox--growth physiology, cell biology, and metabolism. Adv Microb Physiol 2012;60:211-62.

17. Leventhal GE, Boix C, Kuechler U, Enke TN, Sliwerska E, Holliger C, et al. Strain-level diversity drives alternative community types in millimetrescale granular biofilms. Nat Microbiol 2018;3(11):1295-303.

18. Ali M, Wang Z, Salam KW, Hari AR, Pronk M, van Loosdrecht MCM, et al. Importance of Species Sorting and Immigration on the Bacterial Assembly of Different-Sized Aggregates in a Full-Scale Aerobic Granular Sludge Plant. Environ Sci Technol 2019;53(14):8291-301.

19. Qian F, Chen X, Wang J, Shen Y, Gao J, Mei J. Differentiation in Nitrogen-Converting Activity and Microbial Community Structure between Granular Size Fractions in a Continuous Autotrophic Nitrogen Removal Reactor. J Microbiol Biotechnol 2017;27(10):1798-807.

20. Luo J, Chen H, Han X, Sun Y, Yuan Z, Guo J. Microbial community structure and biodiversity of size-fractionated granules in a partial nitritation-anammox process. FEMS Microbiol Ecol 2017;93(6).

21. Bagchi S, Lamendella R, Strutt S, Van Loosdrecht MC, Saikaly PE. Metatranscriptomics reveals the molecular mechanism of large granule formation in granular anammox reactor. Scientific reports 2016;6:28327.

22. Speth DR, In 't Zandt MH, Guerrero-Cruz S, Dutilh BE, Jetten MS. Genome-based microbial ecology of anammox granules in a full-scale wastewater treatment system. Nat Commun 2016;7:11172.

23. Lawson CE, Wu S, Bhattacharjee AS, Hamilton JJ, McMahon KD, Goel R, et al. Metabolic network analysis reveals microbial community interactions in anammox granules. Nat Commun 2017;8:15416.

24. Guo J, Peng Y, Fan L, Zhang L, Ni BJ, Kartal B, et al. Metagenomic analysis of anammox communities in three different microbial aggregates. Environ Microbiol 2015;18(9):2979-93.

25. Bhattacharjee AS, Wu S, Lawson CE, Jetten MSM, Kapoor V, Domingo JWS, et al. Whole-Community Metagenomics in Two Different Anammox Configurations: Process Performance and Community Structure. Environ Sci Technol 2017;51(8):4317-27.

26. Nielsen M, Bollmann A, Sliekers O, Jetten M, Schmid M, Strous M, et al. Kinetics, diffusional limitation and microscale distribution of chemistry and organisms in a CANON reactor. FEMS Microb Ecol 2005;51(2):247-56.

27. Hultman J, Waldrop MP, Mackelprang R, David MM, McFarland J, Blazewicz SJ, et al. Multi-omics of permafrost, active layer and thermokarst bog soil microbiomes. Nature 2015;521(7551):208-12.

28. Youssef N, Sheik CS, Krumholz LR, Najar FZ, Roe BA, Elshahed MS. Comparison of species richness estimates obtained using nearly complete fragments and simulated pyrosequencing-generated fragments in 16S rRNA gene-based environmental surveys. Appl Environ Microbiol 2009;75(16):5227-36.

29. Brown RL, Jacobs LA, Peet RK. Species Richness: Small Scale. Encyclopedia of Life Sciences. 2007.

30. Satoh H, Miura Y, Tsushima I, Okabe S. Layered structure of bacterial and archaeal communities and their in situ activities in anaerobic granules. Appl Environ Microbiol 2007;73(22):7300-7.

31. Rathnayake R, Oshiki M, Ishii S, Segawa T, Satoh H, Okabe S. Experimental Evidence for in Situ Nitric Oxide Production in Anaerobic Ammonia-Oxidizing Bacterial Granules. Environ Sci Technol 2018;52(10):5744-52.

32. Meyer RL, Saunders AM, Zeng RJ, Keller Jr, Blackall LL. Microscale structure and function of anaerobicâه冈aerobic granules containing glycogen accumulating organisms. FEMS Microbiology Ecology 2003;45(3):253-61.

33. Lemaire R, Webb RI, Yuan Z. Micro-scale observations of the structure of aerobic microbial granules used for the treatment of nutrient-rich industrial wastewater. The ISME Journal 2008;2(5):528-41.

34. Raes J, Letunic I, Yamada T, Jensen LJ, Bork P. Toward molecular trait-based ecology through integration of biogeochemical, geographical and metagenomic data. Mol Syst Biol 2011;7:473.

35. Fierera N, Leff JW, Adams BJ, Nielsen UN, Bates ST, Lauber CL, et al. Cross-biome metagenomic analyses of soil microbial communities and their functional attributes. PNAS 2012;109(52):21390-5.

36. Allison SD, Martiny JB. Resistance, resilience, and redundancy in microbial communities. Proc Natl Acad Sci U S A 2008;105 Suppl 1:11512-9.

37. Bardgett RD, van der Putten WH. Belowground biodiversity and ecosystem functioning. Nature 2014;515(7528):505-11.

38. Finlay BJ, Maberly SC, Cooper JI. Microbial Diversity and Ecosystem Function. Nordic Society Oikos 1997;80(2):209-13.

39. Strous M, Van Gerven E, Kuenen JG, Jetten M. Effects of aerobic and microaerobic conditions on anaerobic ammonium-oxidizing (anammox) sludge. Appl Environ Microb 1997;63(6):2446-8.

40. de Kreuk MK, Picioreanu C, Hosseini M, Xavier JB, van Loosdrecht MCM. Kinetic model of a granular sludge SBR: Influences on nutrient removal. Biotechnol Bioeng 2007;97(4):801-15. 
41. Davison J, Moora M, Opik M, Ainsaar L, Ducousso M, Hiiesalu I, et al. Microbial island biogeography: isolation shapes the life history characteristics but not diversity of root-symbiotic fungal communities. ISME J 2018;12:2211-24.

42. Santos AMC, Field R, Ricklefs RE. New directions in island biogeography. Global Ecology and Biogeography 2016;25(7):751-68.

43. Patiño J, Whittaker RJ, Borges PAV, Fernández-Palacios JM, Ah-Peng C, Araújo MB, et al. A roadmap for island biology: 50 fundamental questions after 50 years of The Theory of Island Biogeography. Journal of Biogeography 2017;44(5):963-83.

44. Ali M, Wang Z, Salam K, Hari AR, Pronk M, Van Loosdrecht MC, et al. Importance of species sorting and immigration on the bacterial assembly of different-sized aggregates in a full-scale aerobic granular sludge plant. Environ Sci Technol 2019.

45. Liu T, Ma B, Chen X, Ni B-J, Peng Y, Guo J. Evaluation of mainstream nitrogen removal by simultaneous partial nitrification, anammox and denitrification (SNAD) process in a granule-based reactor. Chemical Engineering Journal 2017;327:973-81.

46. Law Y, Ye L, Wang Q, Hu S, Pijuan M, Yuan Z. IProducing free nitrous acid-A green and renewable biocidal agent-From anaerobic digester liquor. Chem Eng J 2015;259:62-9.

47. Faust K, Raes J. Microbial interactions: from networks to models. Nature Reviews Microbiology 2012;10(8):538.

48. Zhu G, Wang S, Ma B, Wang X, Zhou J, Zhao S, et al. Anammox granular sludge in low-ammonium sewage treatment: Not bigger size driving better performance. Water Res 2018;142:147-58.

49. Guo J, Peng Y, Fan L, Zhang L, Ni BJ, Kartal B, et al. Metagenomic analysis of anammox communities in three different microbial aggregates. Environ Microbiol 2016;18(9):2979-93.

50. Zhao Y, Liu S, Jiang B, Feng Y, Zhu T, Tao H, et al. Genome-Centered Metagenomics Analysis Reveals the Symbiotic Organisms Possessing Ability to Cross-Feed with Anammox Bacteria in Anammox Consortia. Environ Sci Technol 2018;52(19):11285-96.

51. Kuroda K, Nobu MK, Mei R, Narihiro T, Bocher BT, Yamaguchi T, et al. A single-granule-level approach reveals ecological heterogeneity in an Upflow anaerobic sludge blanket Reactor. PloS one 2016;11(12):e0167788.

52. Huws SA, Edwards JE, Kim EJ, Scollan ND. Specificity and sensitivity of eubacterial primers utilized for molecular profiling of bacteria within complex microbial ecosystems. J Microbiol Methods 2007;70(3):565-9.

53. Caporaso JG, Kuczynski J, Stombaugh J, Bittinger K, Bushman FD, Costello EK, et al. QIIME allows analysis of high- throughput community sequencing data. Nature Methods 2010;7(5):335-6.

54. Edgar RC, Haas BJ, Clemente JC, Quince C, Knight R. UCHIME improves sensitivity and speed of chimera detection. Bioinformatics 2011;27(16):2194-200.

55. Quast C, Pruesse E, Yilmaz P, Gerken J, Schweer T, Yarza P, et al. The SILVA ribosomal RNA gene database project: improved data processing and web-based tools. Nucleic Acids Res 2013;41(Database issue):D590-6.

56. Bolger AM, Lohse M, Usadel B. Trimmomatic: a flexible trimmer for Illumina sequence data. Bioinformatics 2014;30(15):2114-20.

57. Peng Y, Leung HC, Yiu SM, Chin FY. IDBA-UD: a de novo assembler for single-cell and metagenomic sequencing data with highly uneven depth. Bioinformatics 2012;28(11):1420-8.

58. Kang DD, Froula J, Egan R, Wang Z. MetaBAT, an efficient tool for accurately reconstructing single genomes from complex microbial communities. PeerJ 2015;3:e1165.

59. Parks DH, Imelfort M, Skennerton CT, Hugenholtz P, Tyson GW. CheckM: assessing the quality of microbial genomes recovered from isolates, single cells, and metagenomes. Genome Res 2015;25(7):1043-55.

60. Li H, Durbin R. Fast and accurate short read alignment with Burrows-Wheeler transform. Bioinformatics 2009;25(14):1754-60.

61. DeSantis TZ, Hugenholtz P, Larsen N, Rojas M, Brodie EL, Keller K, et al. Greengenes, a chimera-checked 16S rRNA gene database and workbench compatible with ARB. Appl Environ Microbiol 2006;72(7):5069-72.

62. Parks DH, Chuvochina M, Waite DW, Rinke C, Skarshewski A, Chaumeil PA, et al. A standardized bacterial taxonomy based on genome phylogeny substantially revises the tree of life. Nat Biotechnol 2018;36(10):996-1004.

63. Price MN, Dehal PS, Arkin AP. FastTree 2 - Approximately Maximum-Likelihood Trees for Large Alignments. PLoS ONE 2010;5(3):1-10.

64. McDonald D, Price MN, Goodrich J, Nawrocki EP, DeSantis TZ, Probst A, et al. An improved Greengenes taxonomy with explicit ranks for ecological and evolutionary analyses of bacteria and archaea. ISME J 2012;6(3):610-8.

65. Ludwig W, Strunk O, Westram R, Richter L, Meier H, Yadhukumar, et al. ARB: a software environment for sequence data. Nucleic Acids Research 2004;32(4):1363-71.

66. Dobin A, Davis CA, Schlesinger F, Drenkow J, Zaleski C, Jha S, et al. STAR: ultrafast universal RNA-seq aligner. Bioinformatics 2013;29(1):1521.

67. Seemann T. Prokka: rapid prokaryotic genome annotation. Bioinformatics 2014;30(14):2068-9.

68. Reichert P. Aquasim 2.0-user manual, computer program for the identification and simulation of aquatic systems. Swiss Federal Institute for Environmental Science and Technology (EAWAG) 1998;219. 
69. Volcke El, Picioreanu C, De Baets B, van Loosdrecht MC. The granule size distribution in an anammox-based granular sludge reactor affects the conversion-implications for modeling. Biotechnol Bioeng 2012;109(7):1629-36.

\section{Tables}

Table 1 Numbers of OTUs from 16S rRNA sequencing and alpha diversity indices

\begin{tabular}{cccccc}
\hline Granule size fractions $(\mathrm{mm})$ & \multicolumn{2}{c}{ OTU richness } & \multicolumn{2}{c}{ OTU diversity } \\
& OTU & ACE & Chao1 & Shannon H & Simpson D \\
\hline$<0.2$ & 356 & $430(404,471)$ & $417(391,462)$ & $3.19(3.16,3.22)$ & $0.1347(0.1311,0.1382)$ \\
$0.2-0.5$ & 352 & $400(382,430)$ & $387(370,418)$ & $3.45(3.43,3.48)$ & $0.1008(0.0982,0.1034)$ \\
$0.5-0.8$ & 413 & $472(451,504)$ & $471(446,515)$ & $3.48(3.45,3.51)$ & $0.1164(0.1130,0.1199)$ \\
$0.8-1.0$ & 416 & $470(450,501)$ & $477(450,524)$ & $3.78(3.76,3.81)$ & $0.0735(0.0712,0.0758)$ \\
$>1.0$ & 434 & $492(471,525)$ & $492(467,536)$ & $3.83(3.80,3.86)$ & $0.0806(0.0780,0.0831)$ \\
\hline
\end{tabular}

Table 2 Characteristics of the 22 draft genomes obtained in this study

\begin{tabular}{lllllllll}
\hline $\begin{array}{l}\text { Bin } \\
\text { ID }\end{array}$ & Phylum & $\begin{array}{l}\text { Draft } \\
\text { genome } \\
\text { size } \\
\text { (Mbp) }\end{array}$ & $\begin{array}{l}\text { Completeness } \\
(\%)\end{array}$ & $\begin{array}{l}\text { Contamination } \\
(\%)\end{array}$ & $\begin{array}{l}\text { Number } \\
\text { of } \\
\text { Scaffolds }\end{array}$ & $\begin{array}{l}\text { N50 } \\
\text { Scaffolds } \\
\text { (bp) }\end{array}$ & $\begin{array}{l}\text { GC } \\
\text { (\%) }\end{array}$ & $\begin{array}{l}\text { Predicted } \\
\text { genes }\end{array}$ \\
\hline ACD1 & Acidobacteria & 4.4 & 95.5 & 0.9 & 48 & 160499 & 71.9 & 3709 \\
\hline ACD2 & Acidobacteria & 4.9 & 99.2 & 2.6 & 31 & 217131 & 61.4 & 4032 \\
\hline AMX & Planctomycetes & 3.7 & 94.5 & 0.6 & 334 & 14490 & 40.6 & 3506 \\
\hline AOB & Proteobacteria & 1.7 & 81.4 & 0.2 & 230 & 9666 & 48.5 & 1717 \\
\hline BCD1 & Bacteroidetes & 3.4 & 98.0 & 1.5 & 164 & 30090 & 41.5 & 2866 \\
\hline BCD2 & Bacteroidetes & 3.8 & 97.0 & 1.5 & 262 & 17852 & 40.5 & 2870 \\
\hline BCD3 & Bacteroidetes & 3.7 & 98.1 & 0.0 & 89 & 54760 & 66.1 & 3183 \\
\hline CFX1 & Chloroflexi & 7.2 & 98.2 & 3.8 & 83 & 136721 & 56.4 & 6159 \\
\hline CFX2 & Chloroflexi & 2.6 & 90.9 & 0.9 & 36 & 144037 & 52.8 & 2471 \\
\hline CFX3 & Chloroflexi & 3.8 & 94.6 & 0.0 & 189 & 33568 & 63 & 3355 \\
\hline CHB1 & Chlorobi & 2.5 & 95.9 & 0.6 & 54 & 92935 & 49.7 & 2097 \\
\hline OP3 & Omnitrophica & 3.7 & 98.9 & 3.4 & 402 & 12882 & 54.6 & 3308 \\
\hline PTB1 & Proteobacteria & 3.8 & 95.5 & 0.9 & 120 & 70698 & 46.8 & 3538 \\
\hline PTB2 & Proteobacteria & 7.2 & 94.5 & 1.8 & 567 & 17391 & 75.1 & 6234 \\
\hline PTB3 & Proteobacteria & 2.9 & 80.4 & 1.0 & 396 & 9156 & 69.6 & 2997 \\
\hline PTB4 & Proteobacteria & 4.1 & 85.7 & 1.0 & 73 & 102162 & 69.7 & 3656 \\
\hline PVC1 & Planctomycetes & 3.7 & 84.1 & 0.0 & 20 & 232630 & 59.4 & 3069 \\
\hline PVC2 & Verrucomicrobia & 1.9 & 86.4 & 0.7 & 193 & 12461 & 57.2 & 1932 \\
\hline PVC3 & Planctomycetes & 3.3 & 96.6 & 0.0 & 36 & 150286 & 70.2 & 2848 \\
\hline PVC4 & Planctomycetes & 5.6 & 97.8 & 3.3 & 37 & 327063 & 57.9 & 3350 \\
\hline PVC5 & Verrucomicrobia & 4.1 & 90.4 & 1.4 & 63 & 150865 & 59.1 & 3311 \\
\hline PVC6 & Planctomycetes & 4.2 & 95.0 & 1.2 & 338 & 18492 & 56.6 & 3623 \\
\hline
\end{tabular}

\section{Figures}




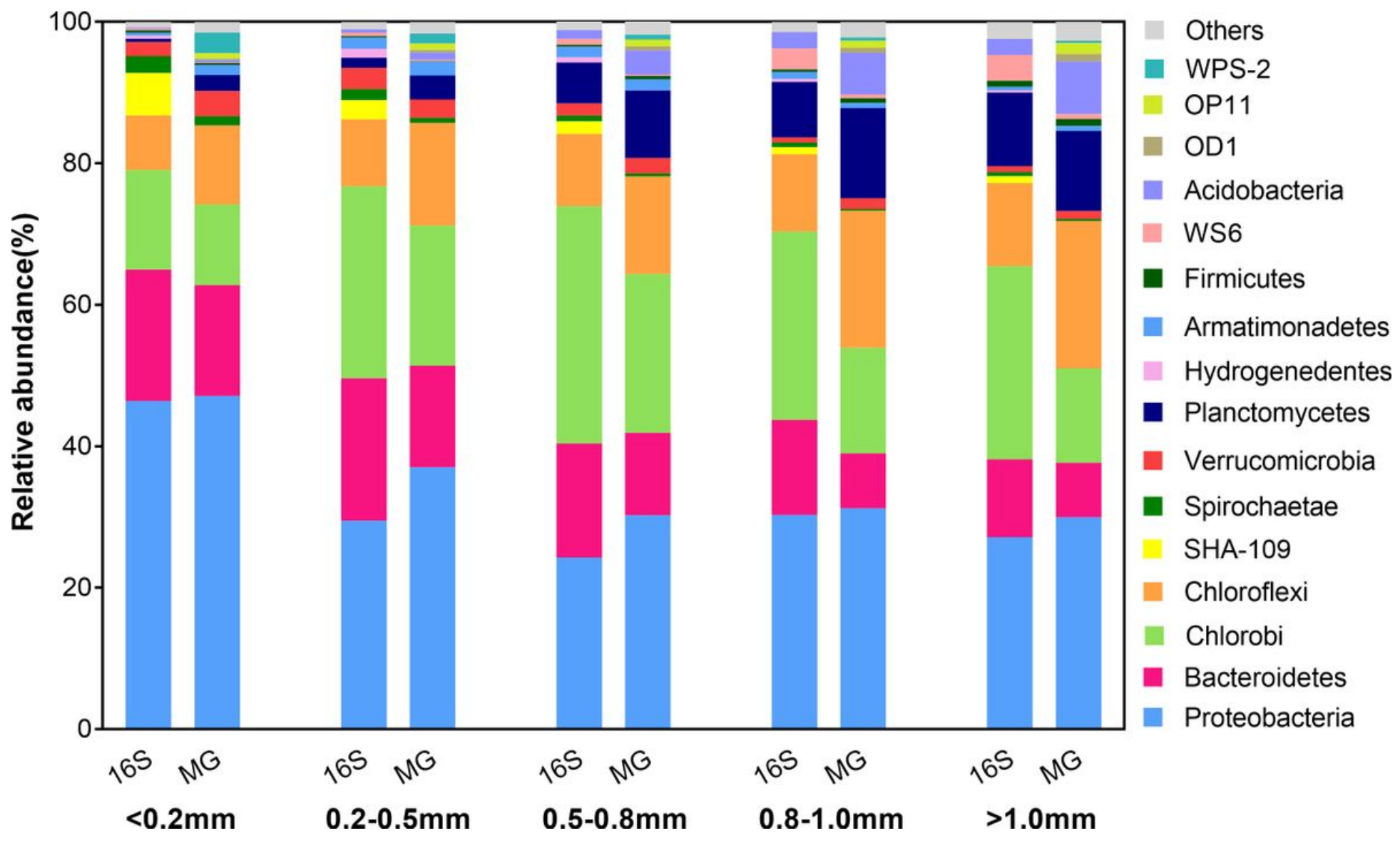

Figure 1

Microbial phylogenetic composition in size-fractionated anammox granules. Relative abundance of phyla on the basis of targeted 16S rRNA gene sequencing (16S), and 16S rRNA genes reads from metagenomes (MG). 


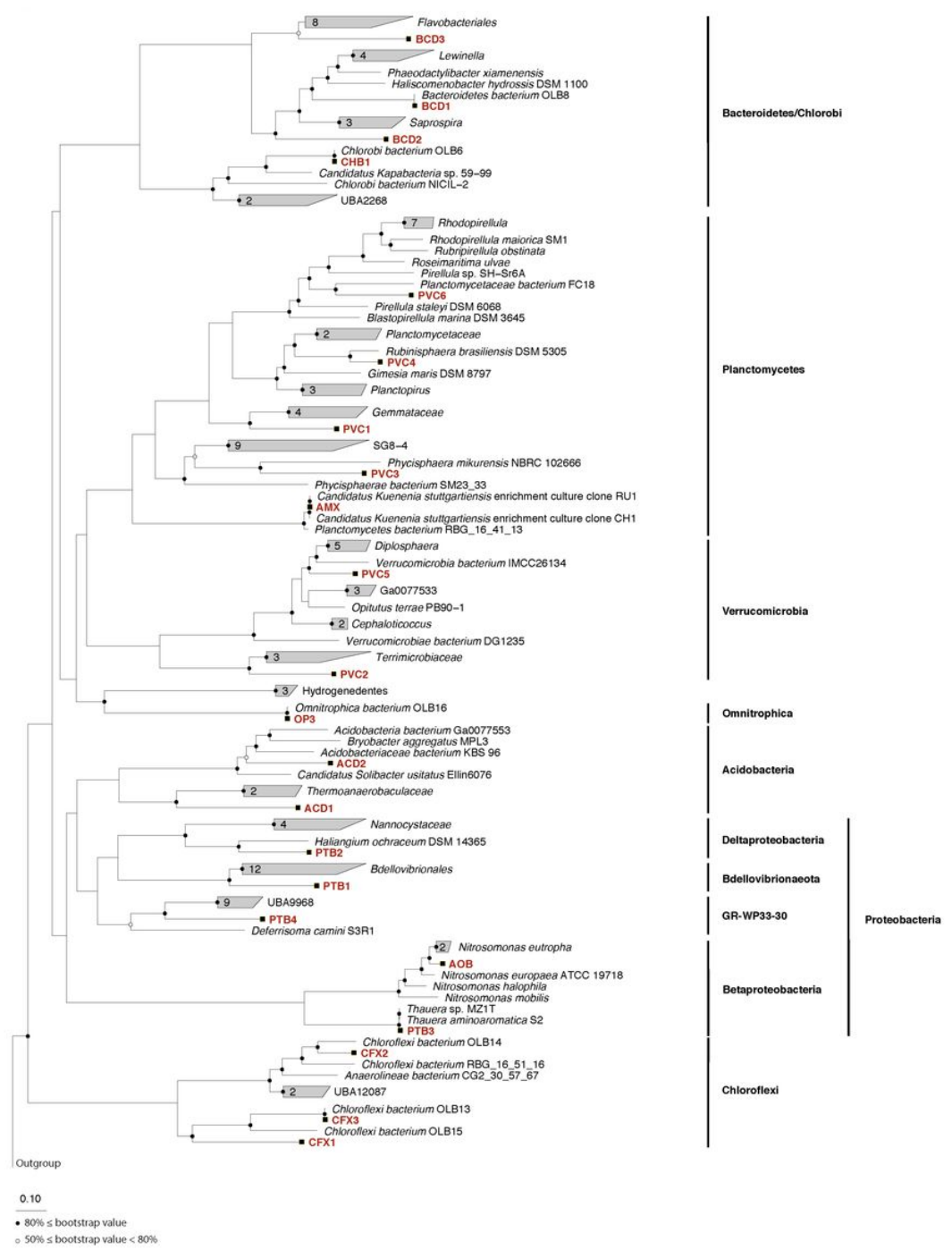

Figure 2

Phylogenetic inference of 22 metagenome-assembled draft genomes (red) based on 120 single copy bacterial marker genes using maximumlikelihood tree. Representative genomes that closely related to the 22 MAGs were shown when available, otherwise the closely related groups were shown as grey blocks. Bootstrap support was generated from 100 replicates. The scale bar represents $10 \%$ nucleotide substitutions. 

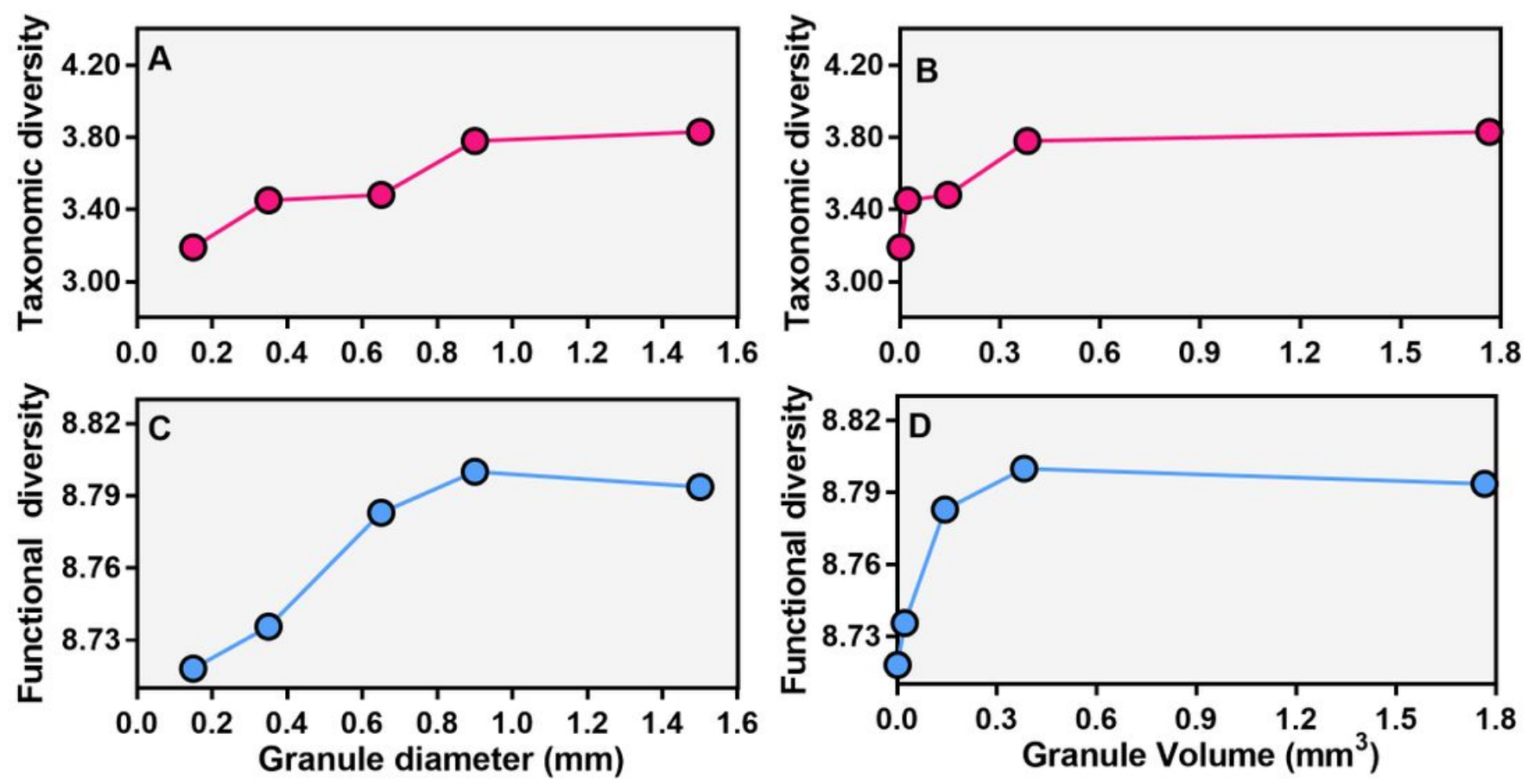

Figure 3

Taxonomic diversity based on 16S rRNA sequencing: (A) diversity vs. the diameter of granule; (B) diversity vs. the volume of granule. And functional diversity based on metagenomic sequencing with the functional annotation against SEED: (C) diversity vs. the diameter of granule; (D) diversity vs. the volume of granule. Diversity was indicated using the Shannon's index $\left(\mathrm{H}^{\prime}\right)$. 


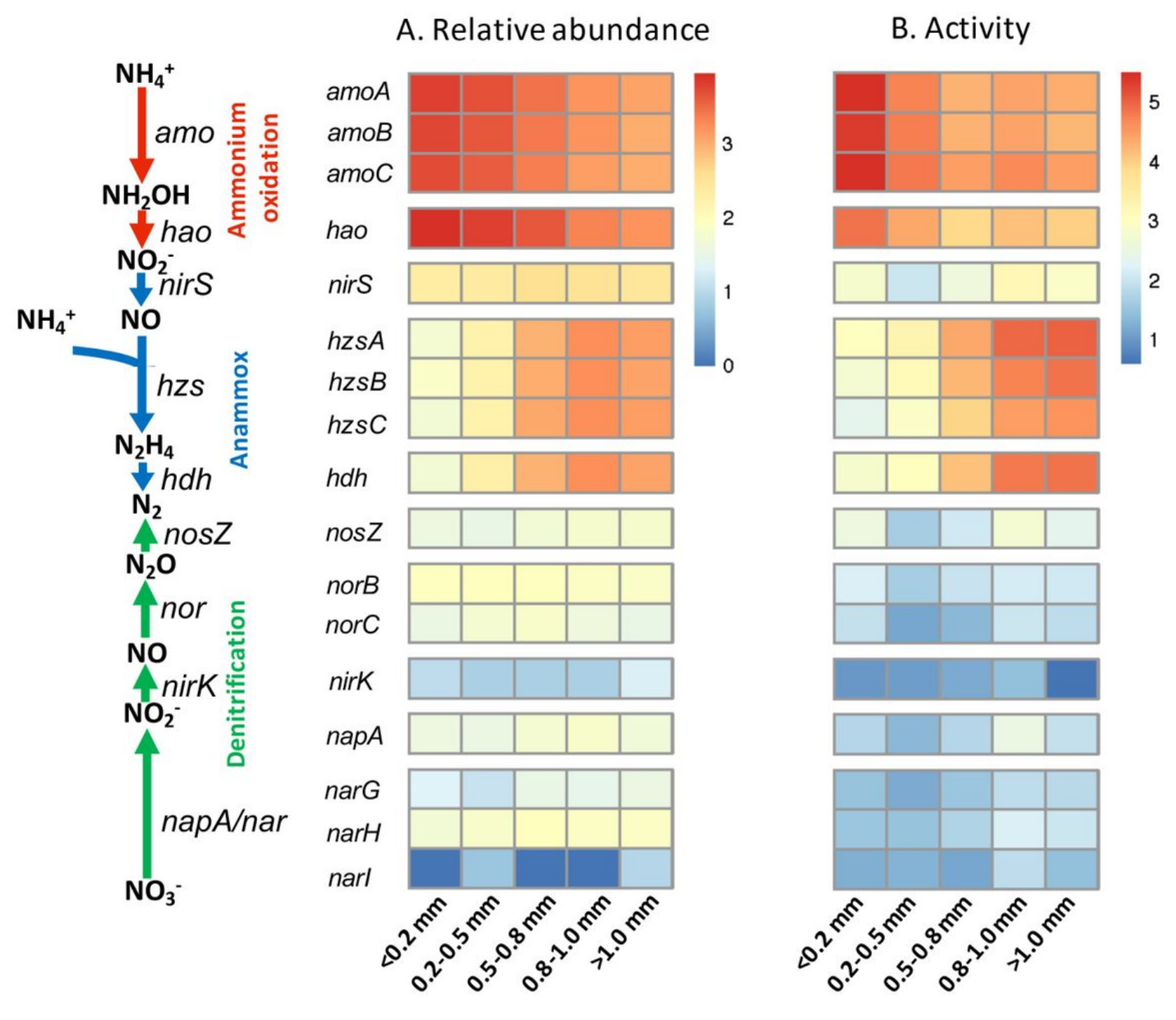

Figure 4

Presence (A) and expression (B) of ammonium oxidation, nitrification and denitrification genes in size-fractionated anammox granule. Color intensity represents the log10-transformed abundance of presence and expression of genes. 


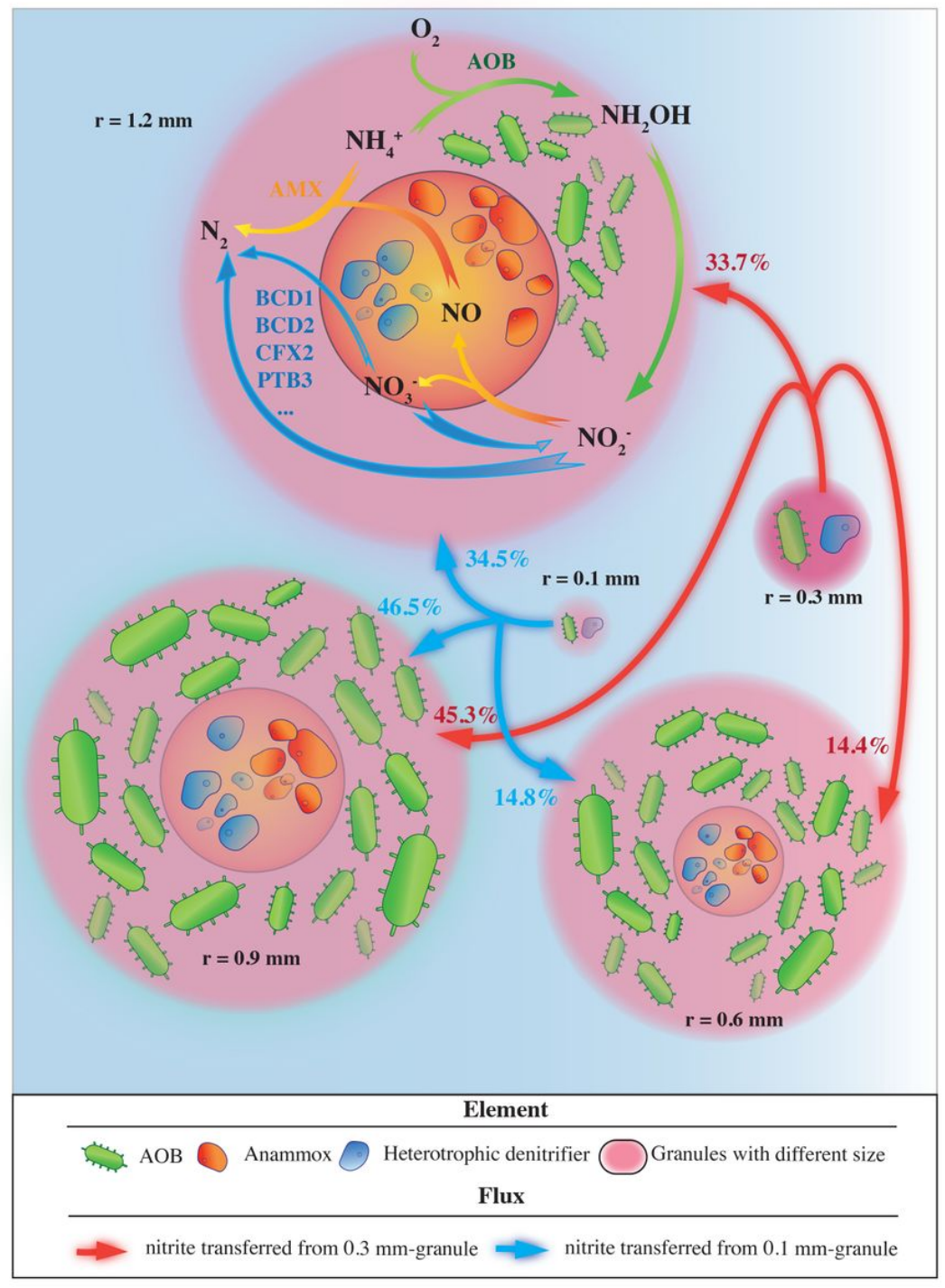

\section{Figure 5}

A proposed ecological model of size-fractioned granules in pilot-scale PN/A reactor. The overview of nitrogen conversion was delineated in granule with radius of $1.2 \mathrm{~mm}$ : ammonium was partially oxidized to nitrite by $A O B$, which were consumed together by $A M X$ to produce nitrogen gas and nitrate; nitrate and nitrite were also consumed by heterotrophic denitrifiers (BCD1, BCD2, CFX2 and PTB3 etc.). The metabolic pathway and responsible enzymes of $\mathrm{AMX}$ and $\mathrm{AOB}$ were delineated in granules with radius of $0.9 \mathrm{~mm}$ and $0.6 \mathrm{~mm}$, respectively. The substrate flux among granules were calculated based on the modelling results.

\section{Supplementary Files}

This is a list of supplementary files associated with this preprint. Click to download.

- SupplementaryInformation.docx 